Research Article

\title{
The Investigation on Heat Transfer Characteristics of Steam Condensation in Presence of Noncondensable Gas under Natural Convection
}

\author{
Xizhen Ma, ${ }^{1,2}$ Jiang $\mathrm{Ma}^{2}{ }^{2}$ Heng Tong, ${ }^{2}$ and Haijun Jia $\mathbb{D}^{3}$ \\ ${ }^{1}$ School of Mechanical and Power Engineering, Zhengzhou University, Zhengzhou, Henan 450001, China \\ ${ }^{2}$ The Boiler \& Pressure Vessel Safety Inspection Institute of Henan Province, Zhengzhou 450016, China \\ ${ }^{3}$ Institute of Nuclear and New Energy Technology, Tsinghua University, Beijing 100084, China
}

Correspondence should be addressed to Haijun Jia; jiaha@mail.tsinghua.edu.cn

Received 13 December 2020; Revised 9 March 2021; Accepted 18 March 2021; Published 26 March 2021

Academic Editor: Leon Cizelj

Copyright (c) 2021 Xizhen Ma et al. This is an open access article distributed under the Creative Commons Attribution License, which permits unrestricted use, distribution, and reproduction in any medium, provided the original work is properly cited.

The NHR-200 reactor in China adopts the noncondensable gas self-stabilizing control and the noncondensable gas used for pressure stabilization control can weaken steam condensation heat transfer in the integrated steam-gas pressurizer. A condensation experimental system was established and the heat transfer characteristics of steam-nitrogen and steam-argon condensation under natural convection had been investigated. The pressure ranged from 0.516 to $5.10 \mathrm{MPa}$. The distributions of nitrogen and argon in the steam/gas mixture were obtained in the experiments, and the results showed that nitrogen and argon were evenly distributed in the steam under different pressure, respectively. The effects of heat transfer temperature difference had also been investigated and it is found that the total heat transfer coefficient difference had little influence on the total condensation heat transfer coefficient. However, the steam condensation heat transfer coefficient decreased with the increase of the degree of supercooling of the wall. The condensation heat transfer coefficient was reduced by approximately $0.11 \mathrm{~kW} /\left(\mathrm{m}^{2} \cdot \mathrm{K}\right)$ as the degree of supercooling of the wall changed from $14^{\circ} \mathrm{C}$ to $36^{\circ} \mathrm{C}$. The condensation heat transfer coefficient also decreased with the mass/molar fraction of noncondensable gas increasing and a certain difference between the effect of the mass fraction of noncondensable gas and the effect of the molar fraction of noncondensable gas was discussed in this paper.

\section{Introduction}

Small- and medium-sized reactors (generally less than $300 \mathrm{MWe}$ ) have become one of the options for future power propulsion due to their high safety and reliability, low power density, short construction period, and so forth. The integrated reactor is one of the main types of small- and medium-sized reactors, such as VVER-300 and VK-300 reactors in Russia, SMART reactor in South Korea, SMR reactors in the United States, and NHR-200 reactor in China [1-3].

The NHR-200 reactor adopts the noncondensable gas self-stabilizing control, that is, the integrated steam-gas pressurizer is adopted and the noncondensable gas is used for the pressure stabilization control [4]. Extremely complicated thermohydraulic phenomena, such as the pressure transient, the stratification of noncondensable gas in the mixed gases, the heat and mass transfer at the steam-liquid interface, and steam condensation in presence of noncondensable gas on the wall, are involved in the steam-gas pressurizer and the existence of noncondensable gas makes these phenomena more complicated. The noncondensable gas will prevent the condensation of steam on the wall and greatly increases the condensation heat transfer thermal resistance, thereby reducing the steam condensation heat transfer coefficient [5].

A lot of experimental research on the effect of noncondensable gas on the steam condensation heat transfer characteristics has been done according to different working conditions and equipment. It is found that when the air concentration was $0.5 \%$, the steam condensation heat transfer coefficient would decrease by $50 \%$ [6]. Uchida et al. selected air, nitrogen, and argon as the noncondensable gas 
and studied the effect of steam condensation heat transfer when the mass fraction of noncondensable gases varied in the range of $10 \%$ to $95 \%[7,8]$. Research on the effect of the inclination angle of the condensing surface on the steam condensation heat transfer in presence of noncondensable gases was conducted by Huhtiniemi and Corradini. It was found that the condensation heat transfer coefficient decreased by $15 \sim 25 \%$ when the inclination angle changed from $0^{\circ}$ to $90^{\circ}$. Moreover, for the condition of low noncondensable gas concentration, the influence of the inclination angle of the condensing surface was small [9]. In order to investigate the condensation heat transfer capacity of steam on the inner surface of the AP600 pressure vessel, Anderson chose two sizes of vessels in the experiments and the noncondensable gases were air and helium, respectively. Experiments showed that when the molar fraction of helium was less than $35 \%$, the influence of helium would be ignored. When the molar fraction of helium was higher than $35 \%$, it would cause stratification of noncondensable gas in the steam [10]. It is well known that there are many factors affecting the steam condensation heat transfer by noncondensable gas, including the type and concentration of noncondensable gases [11-15], the degree of supercooling of condensing surface $[16,17]$, the inclination of condensing surface [18], and the flow rate of mixed gas [19], that is, with the increase of the concentration of noncondensable gas, the steam condensation heat transfer coefficient will decrease significantly. Different kinds of noncondensable gases have different effects on steam condensation heat transfer.

The studies also show that pressure is also an important factor affecting the condensation heat transfer of steam with noncondensable gases. In Dehbi's experiment, the noncondensable gases were air and helium, and the experimental pressures were $0.15 \mathrm{MPa}, 0.3 \mathrm{MPa}$, and $0.45 \mathrm{MPa}$, respectively. It is found that the steam condensation heat transfer coefficient increased significantly with the increase of pressure and decreased slowly with the increase of the degree of supercooling of the wall [20]. Liu et al. conducted the condensation heat transfer experiments with noncondensable gas in the pressure range of $0.248 \sim 0.455 \mathrm{MPa}$ and obtained the empirical correlations between the steam condensation heat transfer coefficient and pressure, steam molar fraction, and temperature difference [13]. Similarly, Li [16], Zhang [21], and others also had obtained the empirical correlations of steam condensation heat transfer related to pressure. The experimental pressure of Kim et al. [5] was $0.1 \sim 2.0 \mathrm{MPa}$, and the noncondensable gas was nitrogen. It is proved that nitrogen was uniformly distributed in the steam at each pressure according to the experimental results.

In summary, the investigations on steam condensation heat transfer in presence of noncondensable gas are mainly focused on the forced convection and low-pressure conditions. There are barely condensation studies on natural circulation and high-pressure conditions. For the experimental studies, the pressure in the reported condensation experiments under natural convection is confined within 2.0 $\mathrm{MPa}$. Therefore, the investigations on heat transfer characteristics of steam condensation in presence of noncondensable gas under natural convection are conducted and an experimental system is established in this paper. The effects of nitrogen and argon on the steam condensation have been investigated and the pressure ranges from 0.516 to $5.10 \mathrm{MPa}$. Some factors, such as the distribution of noncondensable gas in the steam, heat transfer temperature difference, the mass fraction, and molar fraction of noncondensable gas, have been studied in the experiments under high pressure in this paper.

\section{Experimental System and Data Analysis}

2.1. Experimental System. As shown in Figure 1, a steam condensation experimental system has been built and mainly consists of four parts: the primary loop, the secondary cooling loop, the vacuum and gas transmission system, and the data acquisition and control system. During the experiments, steam will be generated in the primary vessel by heating water and enter the noncondensable gas space of the vessel through the steam-liquid interface. Then, steam will be condensed on the outer surface of the condensing section due to the wall subcooling.

The coolant flows in the annular channel inside the condensing section and absorbs the condensation latent heat due to steam condensation on the vertical wall of the stainless steel cylinder. The condensing section consists of a $1.669 \mathrm{~m}$ long and $76 \mathrm{~mm}$ outer diameter, stainless steel cylinder positioned centrally inside the primary vessel. The condensing section consists of an inner tube, $34 \mathrm{~mm}$ outer diameter, and an outer condensing tube, $60 \mathrm{~mm}$ inner diameter. As shown in Figure 2, the wall temperature of the condensing section can be measured in the experiments and five thermocouple wires (TW1-TW5) are welded on the outer surface of the tube by the interval of $300 \mathrm{~mm}$. And five sheathed K-type thermocouples (T201-T205) are fixed at the corresponding position in the annular channel of the tube to obtain the coolant temperature.

The primary vessel is made of stainless steel with $3.66 \mathrm{~m}$ long and $0.4 \mathrm{~m}$ inner diameter. The vessel is fully insulated so that steam condensation will only occur on the stainless steel cylinder. The steam is generated at the bottom of the vessel by a set of electrical heaters with $0 \sim 60 \mathrm{~kW}$ power. The primary vessel is maintained vacuum prior to the condensation experiments and the noncondensable gas is injected into the vessel by the vacuum and gas transmission system. Nitrogen and argon are chosen as the noncondensable gas and investigated in the experiments. The parameters, such as pressure, differential pressure, temperature, and mass flow rate, are measured and acquired in the experiments.

2.2. Data Analysis. The temperature, which consists of the wall temperature of the condensing section, the steam/ noncondensable gas bulk temperature, and the coolant temperature of the secondary cooling loop, is measured in the experiments. The pressure in the primary vessel and in the secondary cooling loop is also obtained. It is assumed that the steam shares the same temperature with the noncondensable gas in the primary vessel during the 


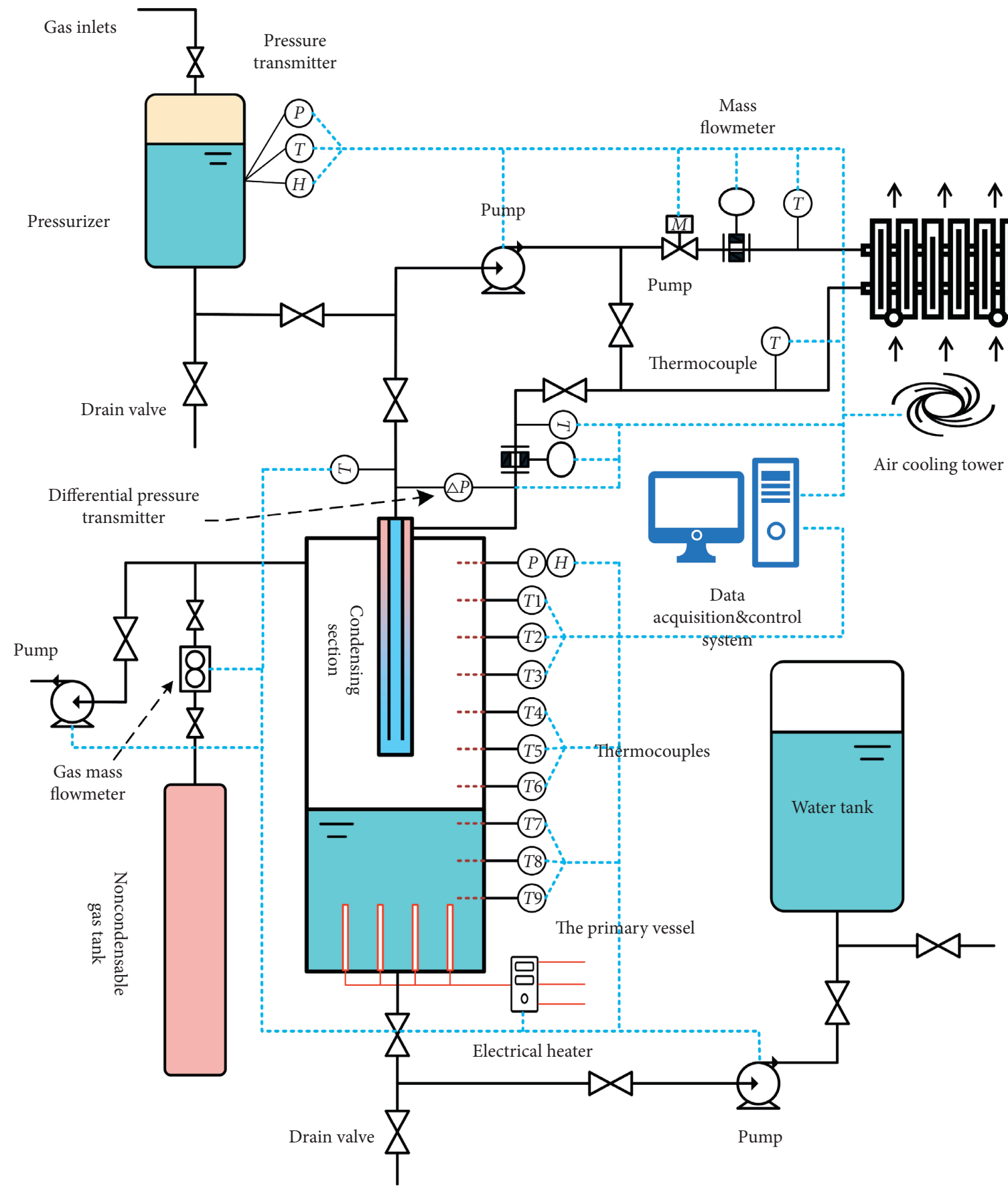

Figure 1: The steam condensation experimental system under natural convection.

experiments. What is more, the radial temperature difference of the steam/gas mixture in the vessel is neglected.

Due to the presence of noncondensable gas, the measured steam temperature is less than the steam saturation temperature corresponding to the current bulk pressure. So, the axial steam temperature profile can be used to figure out the noncondensable gas concentration variation in the axial direction [20]. Assuming steam is always at saturation at any temperature, the steam partial pressure in the steam/gas mixture can be easily given by

$$
P_{n}=P_{t}-P_{s}\left(T_{x}\right)
$$

Depending on Dalton's law of partial pressure [22], the ratio of the mass of noncondensable gas to the mass of steam is

$$
\frac{m_{n}}{m_{s}}=\frac{P_{n}}{P_{s}\left(T_{x}\right)} \cdot \frac{M_{n}}{M_{s}}=\frac{P_{t}-P_{s}\left(T_{x}\right)}{P_{s}\left(T_{x}\right)} \cdot \frac{M_{n}}{M_{s}} .
$$

The mass fraction of the noncondensable gas $W_{n}(x)$ is defined as 


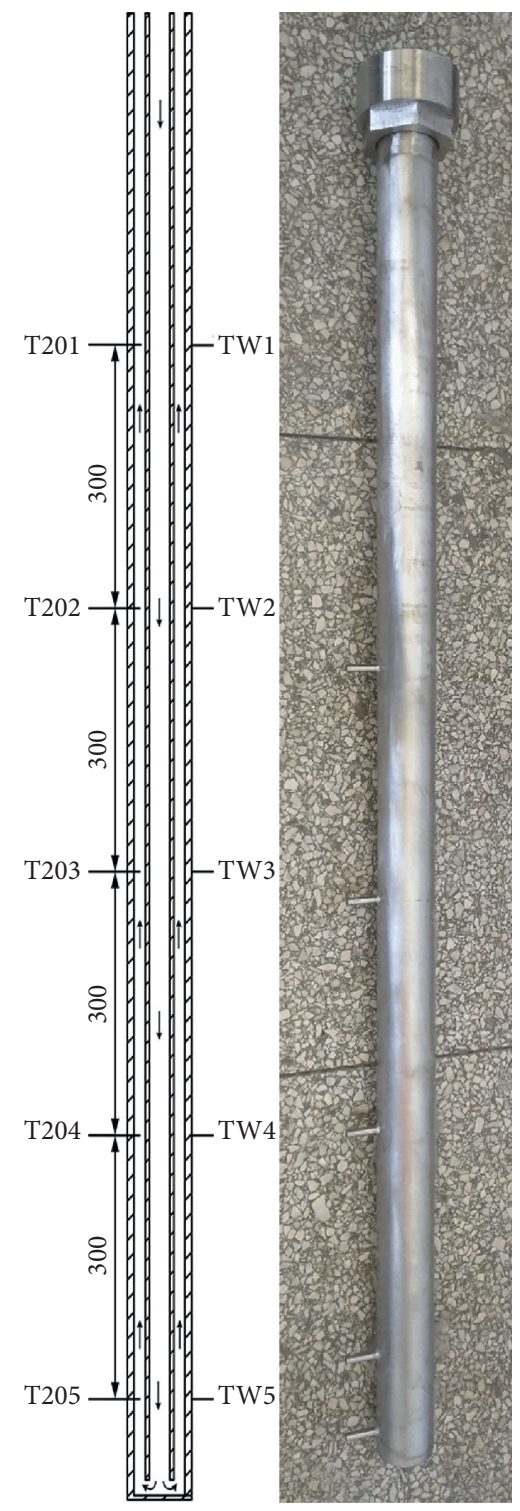

Figure 2: Temperature measurements of the condensing section.

$$
W_{n}(x)=\frac{m_{n}}{m_{n}+m_{s}}=\frac{\left(m_{n} / m_{s}\right)}{1+\left(m_{n} / m_{s}\right)} .
$$

Therefore,

$$
W_{n}(x)=\frac{P_{t}-P_{s}\left(T_{x}\right)}{P_{t}-P_{s}\left(T_{x}\right)\left(1-\left(M_{s} / M_{n}\right)\right)} .
$$

In the same way, the molar fraction of noncondensable gas $X_{n}(x)$ can be obtained as

$$
X_{n}(x)=\frac{P_{n} Z_{s}}{P_{n} Z_{s}+P_{s}\left(T_{x}\right) Z_{n}}=\frac{P_{t}-P_{s}\left(T_{x}\right)}{P_{t}-P_{s}\left(T_{x}\right)\left(1-\left(Z_{n} / Z_{s}\right)\right)},
$$

where $Z$ is the compressibility factor of gas. Due to the highpressure condition in the experiments, the compression effect of high pressure on the steam/gas is obvious and should be taken into account. $Z$ can be given by the pressure and temperature.

The effect of the curvature of the condensing cylinder should be also taken into account. The heat transfer on the cylinder surface can be enhanced compared to the flat plate surface. However, the outer diameter of the condensing cylinder in the experiments is $76 \mathrm{~mm}$, far greater than the thickness of the condensate film. Therefore, the enhancement of curvature of the condensing cylinder on steam condensation is ignored.

For a length $L$ of the condensing cylinder, the average condensation heat transfer coefficient of steam, $\overline{h_{L}}$, and the heat transfer rate of steam condensation, $Q$, are defined as follows [23]:

$$
\begin{array}{r}
\overline{h_{L}}=\frac{\dot{M}\left(h_{\text {out }}-h_{\text {in }}\right)}{\pi D_{o} L\left(\overline{T_{\infty}}-\overline{T_{w}}\right)}, \\
Q=\dot{M}\left(h_{\text {out }}-h_{\text {in }}\right) .
\end{array}
$$

What is more, the steam condensation rate is calculated as

$$
\overline{h_{L}}=\frac{\dot{M}\left(h_{\mathrm{out}}-h_{\mathrm{in}}\right)}{\pi D_{o} L\left(\overline{T_{\infty}}-\overline{T_{w}}\right)} .
$$

\section{Results and Discussion}

3.1. The Distribution of Noncondensable Gas in the Steam/Gas Mixture. The distribution of noncondensable gas in the mixture space is a vital factor affecting the heat transfer characteristics of steam condensation. Assume that the concentration of noncondensable gas in the radial direction is constant and the difference in the concentration of noncondensable gas in the axial direction is only taken into account. Usually, the general distribution of noncondensable gas in steam can be judged by the molar mass of noncondensable gas; that is, the lighter gas (the molar mass of gas is less than the molar mass of steam) is mainly distributed in the upper space due to the effect of buoyancy. The heavier gas (the molar mass of gas is larger than that of steam) is mainly distributed in the lower space.

However, in the condensation experiments (the experimental conditions of condensation are shown in Table 1), due to the continuous generation of steam in the liquid space, the steam with a certain initial velocity will carry parts of noncondensable gas upward during the ascent, which makes the distribution of noncondensable gas in the steam more uniform to a certain extent [24, 25].

Nitrogen and argon were selected and the distributions of nitrogen/argon in the mixture space under natural convection were studied in the experiments, as shown in Figures 3 and 4.

According to the pressure and temperature in the axial direction in the primary vessel, the mass fraction of nitrogen/ argon can be calculated. The distributions of nitrogen are illustrated in Figure 3. It is indicated that the mass fraction of nitrogen in the axial direction is relatively evenly distributed as the primary pressure increases from 0.517 to $5.10 \mathrm{MPa}$ and 
TABLE 1: Experimental conditions of steam condensation in the presence of nitrogen/argon.

\begin{tabular}{lc}
\hline Parameter & Value \\
\hline Pressure in the primary vessel/MPa & $0.516 \sim 5.10$ \\
Temperature in the primary vessel $/{ }^{\circ} \mathrm{C}$ & $80 \sim 267$ \\
Pressure in the coolant loop $/ \mathrm{MPa}$ & $0.40 \sim 3.2$ \\
Temperature difference between the inlet and outlet of the condensing section $/{ }^{\circ} \mathrm{C}$ & $10 \sim 20$ \\
Mass flow rate of coolant $/ \mathrm{t} / \mathrm{h}$ & $0 \sim 8.5$ \\
Mass fraction of $\mathrm{N}_{2} / \mathrm{Ar}$ & $10 \% \sim 85 \%$ \\
\hline
\end{tabular}

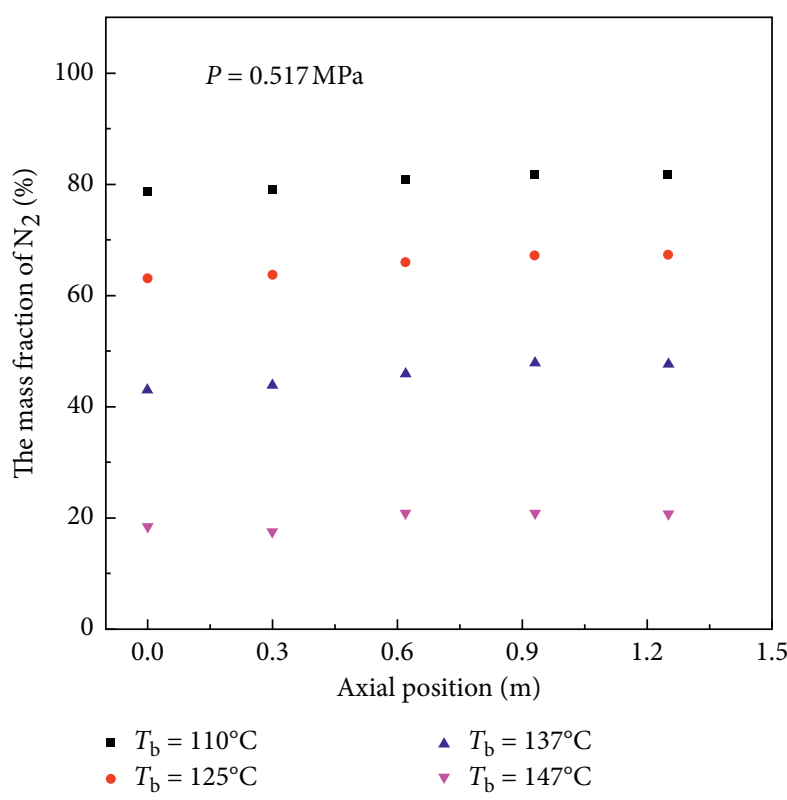

(a)

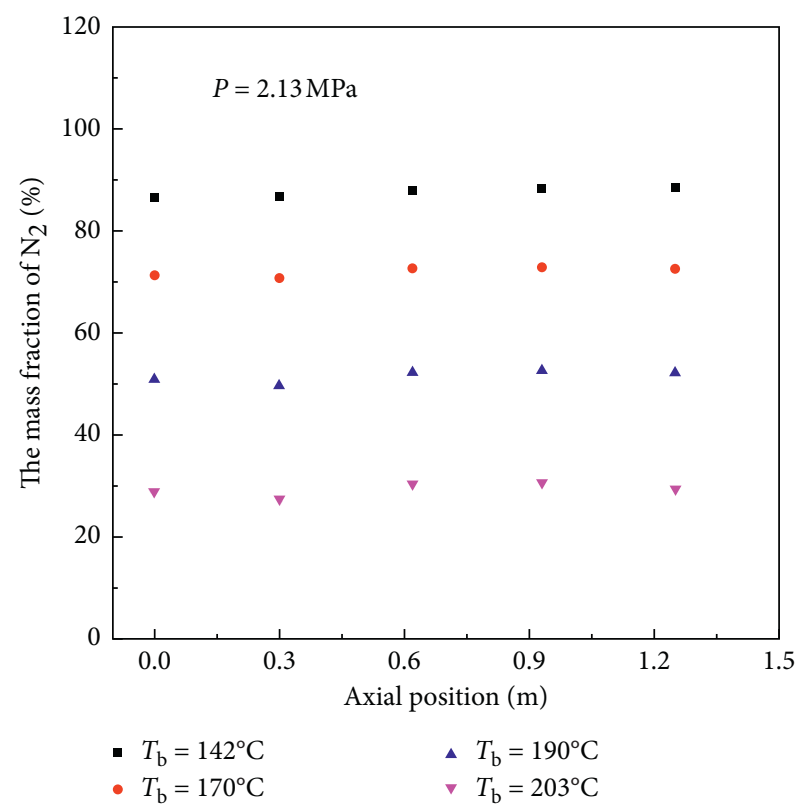

(c)

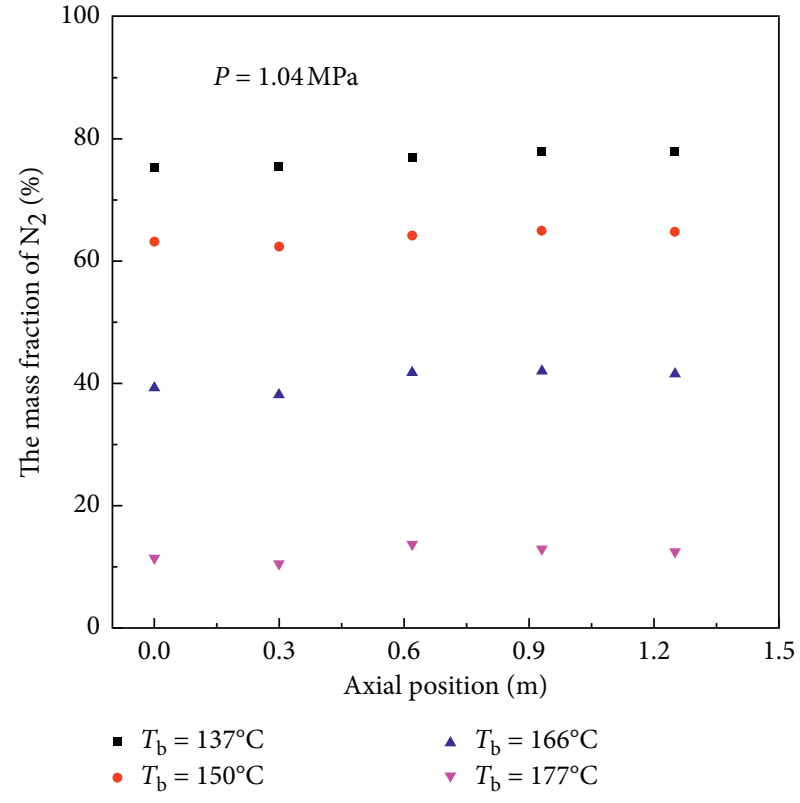

(b)

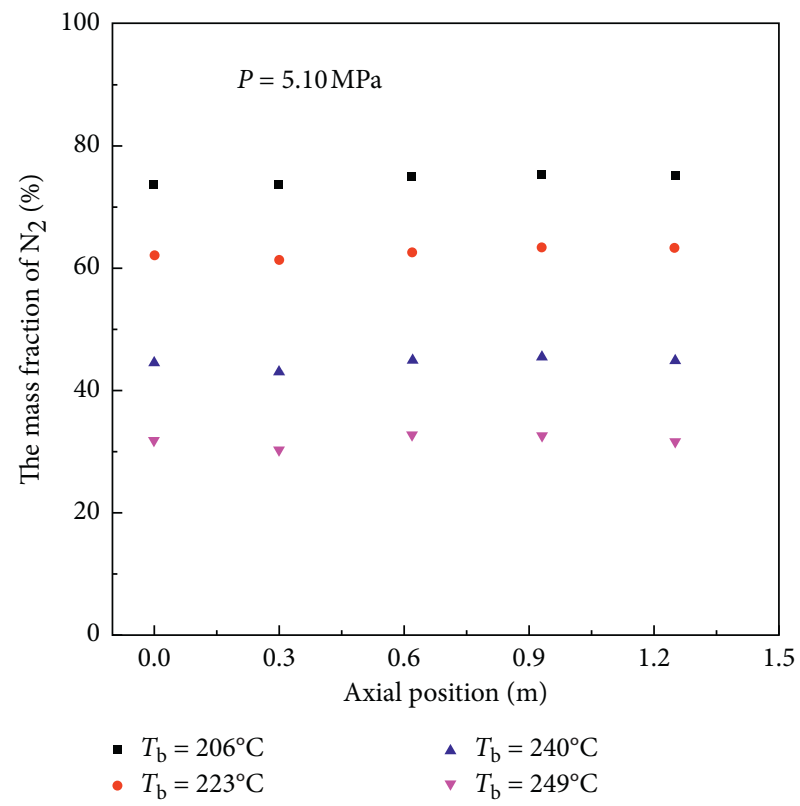

(d)

Figure 3: The distributions of $\mathrm{N}_{2}$ in the axial direction. (a) $P=0.517 \mathrm{MPa}$. (b) $P=1.04 \mathrm{MPa}$. (c) $P=2.13 \mathrm{MPa}$. (d) $P=5.10 \mathrm{MPa}$. 


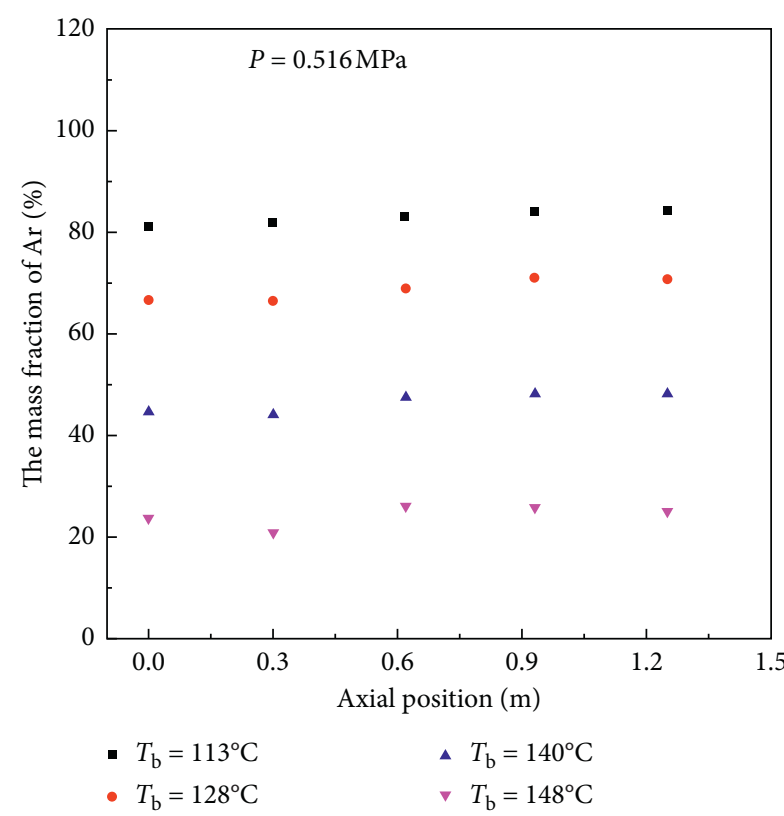

(a)

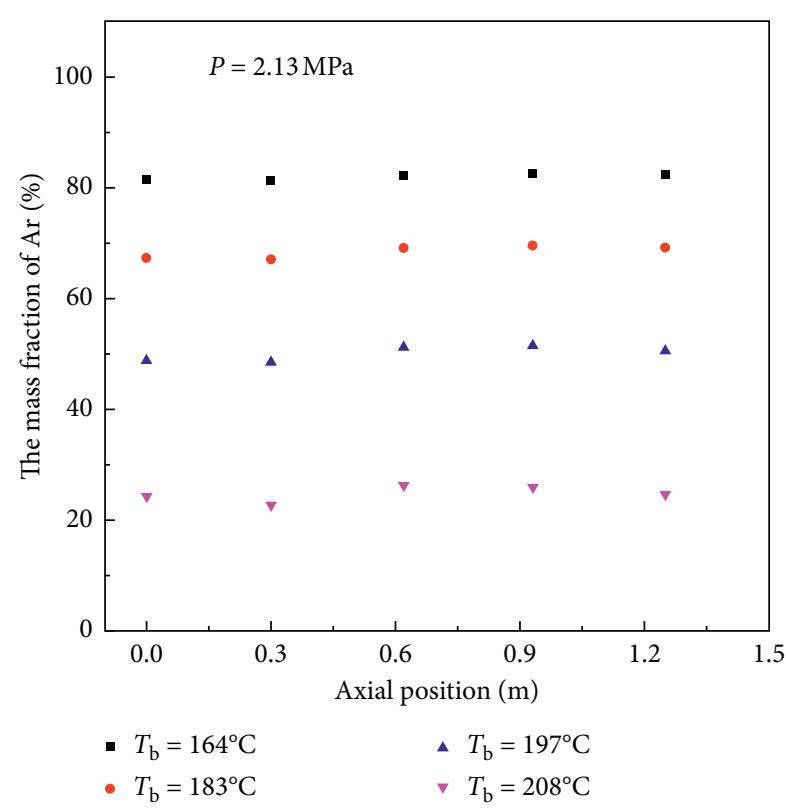

(c)

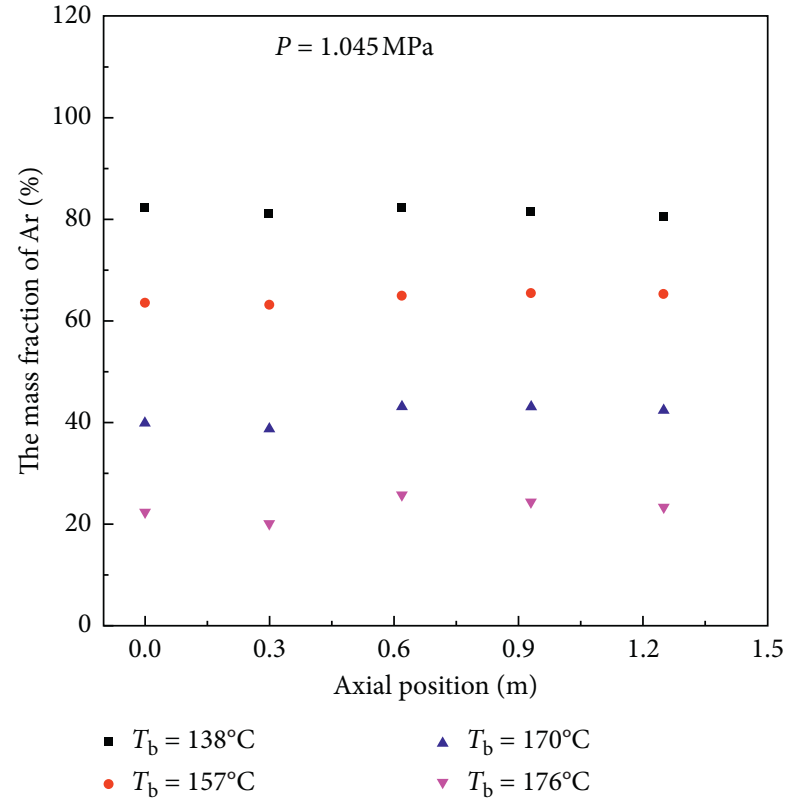

(b)

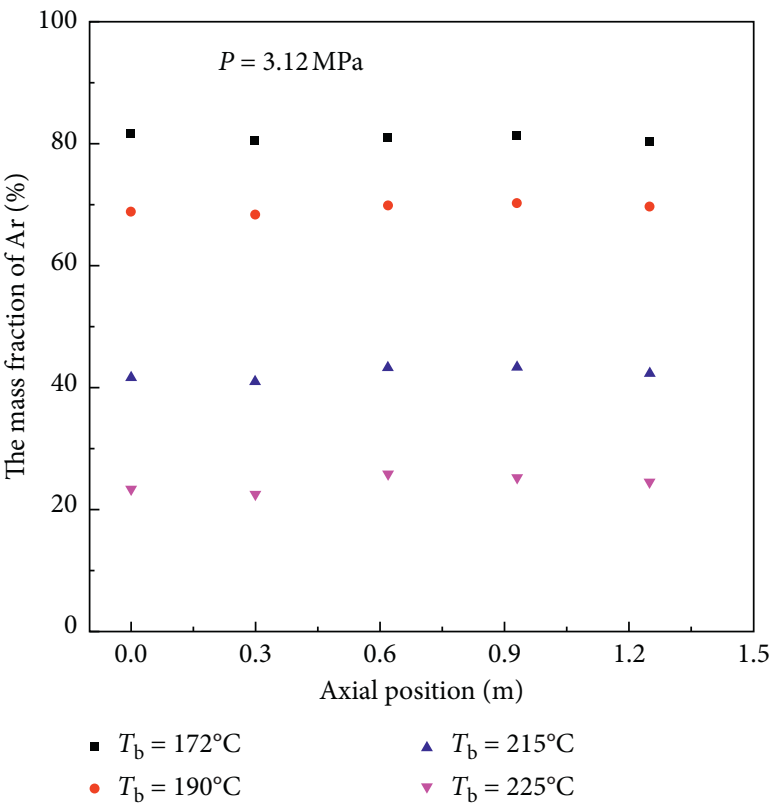

(d)

Figure 4: The distributions of Ar in the axial direction. (a) $P=0.516 \mathrm{MPa}$. (b) $P=1.045 \mathrm{MPa}$. (c) $P=2.13 \mathrm{MPa}$. (d) $P=3.12 \mathrm{MPa}$.

the gas temperature is from $110^{\circ} \mathrm{C}$ to $249^{\circ} \mathrm{C}$. The differences in the mass fraction of nitrogen are little and have similar trends when the axial distance increases. When the primary pressure is $0.517 \mathrm{MPa}$ and the steam temperature is $110^{\circ} \mathrm{C}$, the mass fraction of nitrogen slightly increases from $78.62 \%$ to $81.07 \%$ along the axial direction. When the axial position changes from 0 to $0.62 \mathrm{~m}$, the mass fraction of nitrogen increases from $78.62 \%$ to $80.68 \%$. However, the mass fraction of nitrogen stays around $81 \%$ with the axial position of 0.62 to $1.251 \mathrm{~m}$. The mass fraction of nitrogen in the axial direction shows the same change law as the steam temperature is $125^{\circ} \mathrm{C}, 137^{\circ} \mathrm{C}$, and $147^{\circ} \mathrm{C}$, respectively.
The distributions of nitrogen also have the same characteristics in the axial direction under other pressure conditions, such as $1.04 \mathrm{MPa}, 2.13 \mathrm{MPa}$, and $5.10 \mathrm{MPa}$. And the differences in mass fraction along the axial direction are getting smaller with the increase of pressure. The reason for these is that the smaller the axial position distance is, the closer it is to the lower liquid space. As the system is in a steady state during the condensation experiments, the steam is continuously generated in the liquid space and transferred into the steam/gas mixture space, so the closer to liquid is, the larger the steam mass fraction is and the smaller the corresponding mass fraction of nitrogen is. 
In general, the difference in nitrogen mass fraction along the axial direction is small and can be ignored. The spatial distribution of nitrogen is relatively uniform, and there is no obvious stratification phenomenon in the steam/gas mixture. This is the result of the natural circulation flow of steam in space and the downward flow trend of nitrogen because its molar mass is slightly larger than that of steam.

The distributions of argon are illustrated in Figure 4 and have similar characteristics to the distributions of nitrogen. Although the molar mass of argon is larger than steam, the steam, generated in the liquid space, with a certain initial velocity carries parts of argon upward and results in relatively uniform distributions of argon in the axial direction.

\subsection{Effect of Heat Transfer Temperature Difference on Steam} Condensation Heat Transfer in Presence of Noncondensable Gas. During the experiments, the primary pressure and temperature vary with the operating conditions' parameters such as the concentration of noncondensable gas, while the change of the secondary loop temperature relatively lags behind, which leads to great difficulties in controlling the condensation experiments. Therefore, the control scheme of the total heat transfer temperature difference between the primary and secondary loops varying with the concentration of noncondensable gas is adopted in the experiments. Before investigating the effect of noncondensable gas on the heat and mass transfer of steam condensation, it is necessary to determine the influences of the total heat transfer temperature difference between the primary and secondary loops on the heat transfer of steam condensation with noncondensable gas.

When discussing the influences of the total heat transfer temperature difference on the steam condensation heat transfer, a set of experimental conditions were selected for discussion; that is, the total pressure of the system was approximately $0.520 \mathrm{MPa}$ and nitrogen with a mass fraction of $47 \%$ was chosen. The main control scheme was that the frequency of the pump in the secondary loop was kept as constant as possible, and the system automatically adjusted the total temperature difference between the primary and secondary loops by adjusting the heating rod power to maintain the total pressure in the primary loop at about $0.520 \mathrm{MPa}$, and the nitrogen mass fraction was also maintained at about $47 \%$.

When the experimental system reached a steady state and the frequency of the pump in the second loop was kept unchanged, at first, because the temperature in the secondary loop was the lowest, the total heat transfer temperature difference was the largest. The primary loop was always maintained at a steady state over time, while the second loop was gradually heated by the primary loop due to the heat transfer between the primary and secondary loops. The total heat transfer temperature difference decreased gradually over time.

The range of the total heat transfer temperature difference is $41 \sim 110^{\circ} \mathrm{C}$, and the temperature difference between the inlet and outlet of the condensing section was $5 \sim 10^{\circ} \mathrm{C}$.
The pressure and flow rate of the secondary loop are shown in Figure 5.

It is indicated that the inlet and outlet temperature of the condensing section gradually increases with the decrease of the total heat transfer temperature difference in Figure 5. What is more, the coolant of the secondary loop is gradually heated by the primary loop, which gradually leads to an increase of the pressure in the secondary loop. And the physical parameters of coolant in the secondary, such as the density and the viscosity, change accordingly and the coolant flow rate decreases. It is because that the total heat transfer temperature difference and the heat transfer of the steam condensation decrease gradually, resulting in the gradual decrease of the heat taken away by the secondary loop, while the frequency of the circulation pump of the secondary loop remains unchanged. The automatic control scheme was adopted in the experiments; according to the conservation of energy, the coolant circulation flow rate of the secondary loop decreased gradually.

As shown in Figure 6, when the pressure is $0.520 \mathrm{MPa}$ and the mass fraction of nitrogen is $47 \%$, the total heat transfer coefficient of steam condensing on the vertical wall is about $0.215 \mathrm{~kW} /\left(\mathrm{m}^{2} \cdot \mathrm{K}\right)$, and the heat transfer coefficient remains basically unchanged with the increase of the total heat transfer temperature difference. When the total heat transfer temperature difference is less than $70^{\circ} \mathrm{C}$, the total heat transfer coefficient is always slightly larger than $0.215 \mathrm{~kW} /\left(\mathrm{m}^{2} \cdot \mathrm{K}\right)$. And then the total heat transfer coefficient is slightly less than $0.215 \mathrm{~kW} /\left(\mathrm{m}^{2} \cdot \mathrm{K}\right)$ as the total heat transfer temperature difference is greater than $70^{\circ} \mathrm{C}$. This is because when the total heat transfer temperature increases, the heat transfer in the steam condensation is enhanced, and the amount of steam condensing on the vertical wall increases subsequently, resulting in the thickening of the condensate film, which increases the heat transfer resistance, and the total heat transfer coefficient will decrease.

However, the thickness of the condensate film in the experiments is far smaller than the diameter of the condensing section, and the effect of the increase in the thickness of condensate film on the total heat transfer resistance is very limited. Therefore, as the total heat transfer temperature difference varies from $41^{\circ} \mathrm{C}$ to $110^{\circ} \mathrm{C}$, the change of the total heat transfer coefficient is within $0.016 \mathrm{~kW} /$ $\left(\mathrm{m}^{2} \cdot \mathrm{K}\right)$, which can be tolerated.

The steam condensation heat transfer has been paid more attention and closely related to the condensation heat transfer temperature difference in the experiments. The condensation heat transfer temperature difference refers to the temperature difference between the bulk temperature in the primary loop and the temperature of the vertical condensation wall. Usually, the bulk temperature in the primary loop is considered to be equal to the steam saturation temperature, so the condensation heat transfer temperature difference is also called the degree of supercooling of the wall, which is controlled by the flow rate of coolant in the secondary loop in the experiments.

It is known that the degree of supercooling of the wall is a vital parameter affecting the steam condensation on the wall, 


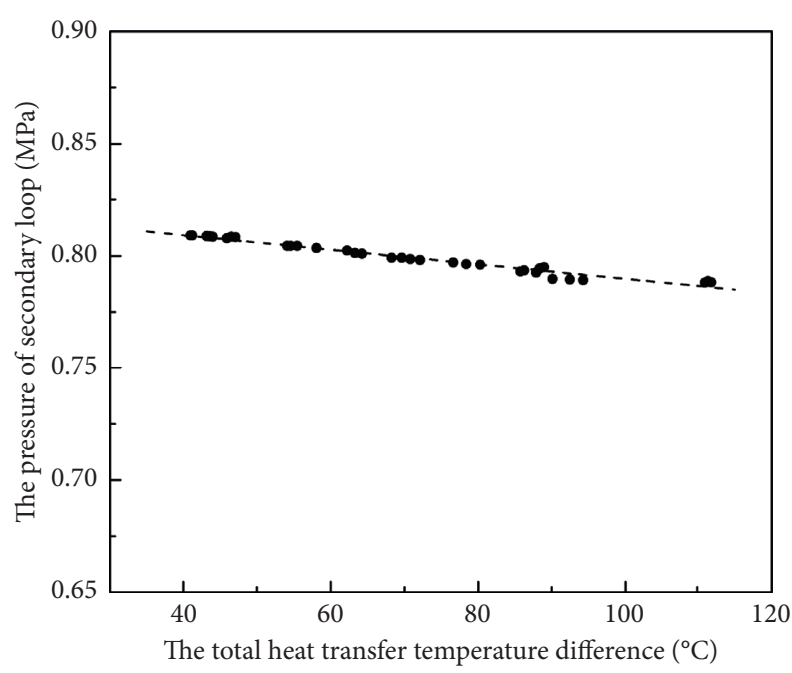

- The pressure of secondary loop

(a)

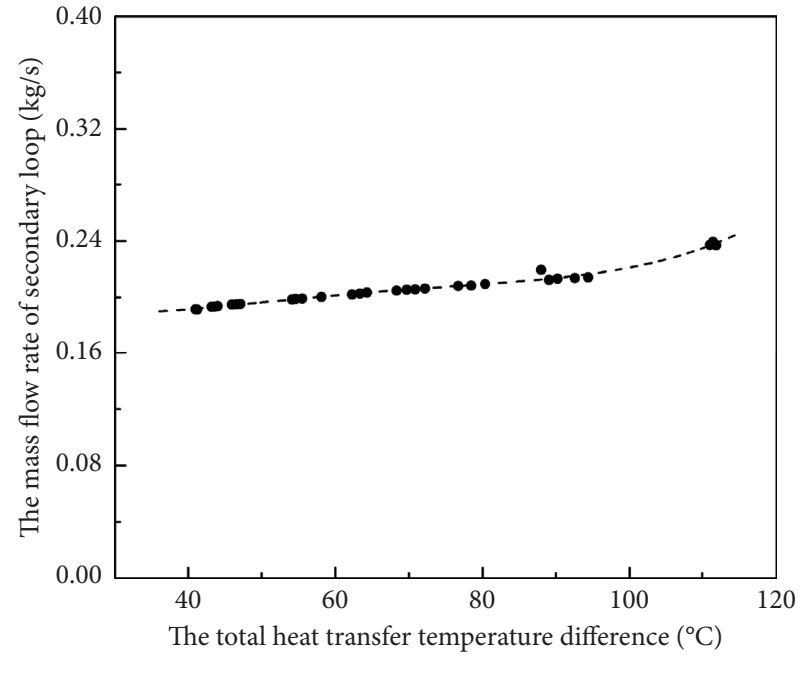

- The mass flow rate of secondary loop

(b)

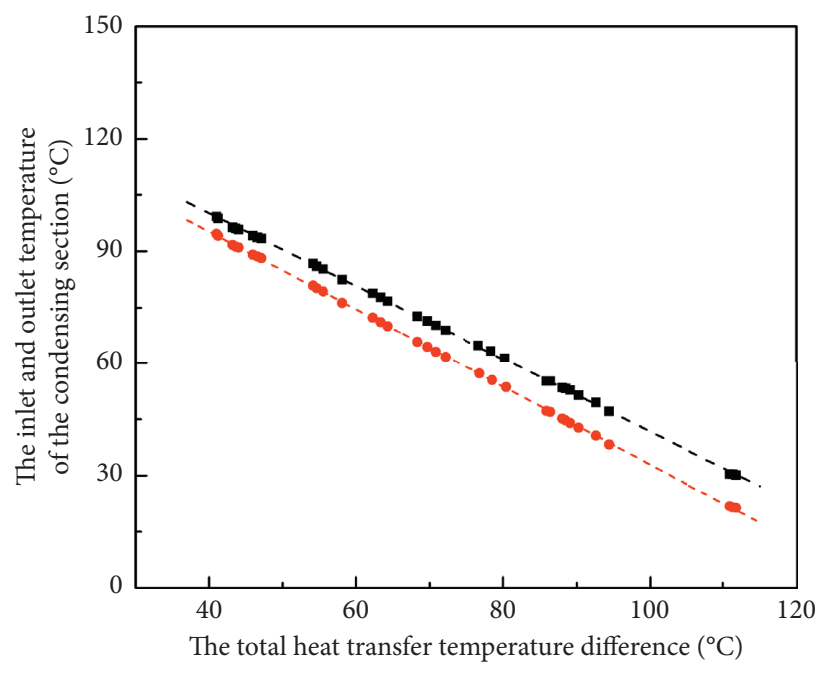

- The inlet temperature

- The outlet temperature

(c)

Figure 5: The pressure and flow rate of the secondary loop. (a) The pressure in the secondary loop. (b) The flow rate of the secondary loop. (c) The inlet and outlet temperature of the condensing section.

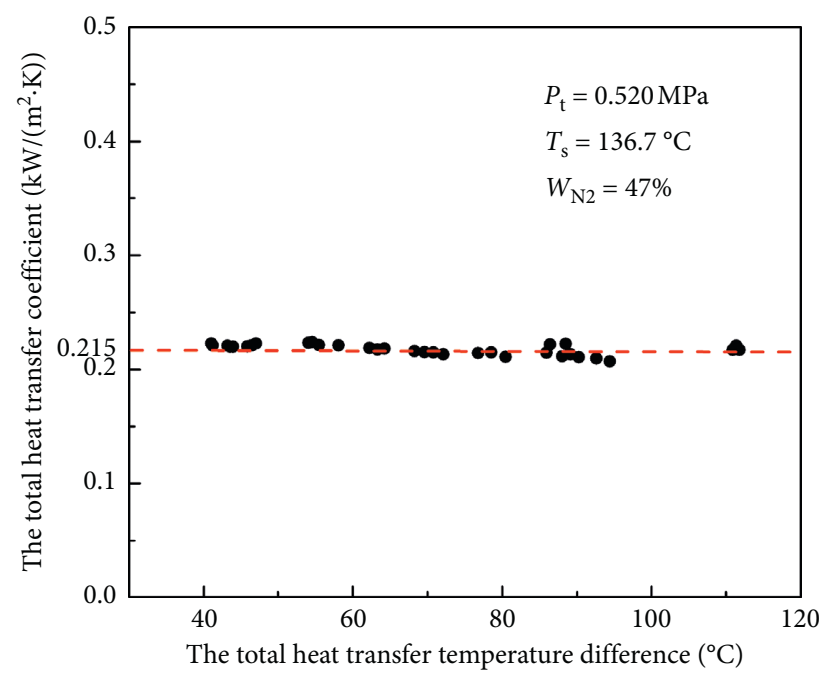

FIgURE 6: The effect of total heat transfer temperature difference on steam condensation. 
and its influence on the heat transfer coefficient of steam condensation also needs to be determined.

As shown in Figure 7, it is obvious that the heat transfer coefficient of steam condensation decreases with the increase of the degree of supercooling of the wall as the primary pressure is $0.520 \mathrm{MPa}$ and the mass fraction of nitrogen is $47 \%$. When the degree of supercooling of the wall is approximately $14^{\circ} \mathrm{C}$, the steam condensation heat transfer coefficient is $0.649 \mathrm{~kW} /$ $\left(\mathrm{m}^{2} \cdot \mathrm{K}\right)$. While the steam condensation heat transfer coefficient is $0.539 \mathrm{~kW} /\left(\mathrm{m}^{2} \cdot \mathrm{K}\right)$ as the degree of supercooling of the wall is about $36^{\circ} \mathrm{C}$. The curve of steam condensation heat transfer coefficient with the degree of supercooling of the wall is close to the polynomial function.

In conclusion, the total heat transfer temperature difference has little influence on the total heat transfer coefficient in the experiments. Therefore, in order to facilitate the control, the variable temperature difference control scheme was adopted in the experiments; that is, the parameters such as the temperature and pressure of the primary loop are adjusted by changing the flow rate of coolant in the secondary loop and the flow into the air cooling tower. What is more, the degree of supercooling of the wall is an important factor affecting the heat transfer of steam condensation on the wall. With the increase of the degree of supercooling of the wall, the steam condensation heat transfer coefficient decreases gradually. Therefore, the degree of supercooling of the wall should be controlled in a very small range as far as possible during the experiments.

\subsection{Effect of Noncondensable Gas on Steam Condensation} Heat Transfer. By forming a thin layer of noncondensable gas between the steam/gas mixture and the condensate film, the noncondensable gas prevents the steam from being close to the condensing surface and forms a large thermal resistance, which weakens the heat and mass transfer in the steam condensation. Therefore, the concentration of noncondensable gas is one of the most important factors affecting the heat and mass transfer in steam condensation. The more the concentration of the noncondensable gas is, the thicker the layer of the noncondensable gas is formed, resulting in greater thermal resistance. Usually, two parameters, mass fraction and molar fraction, are used to describe the concentration of noncondensable gas.

3.3.1. Effect of the Mass Fraction of Noncondensable Gas. As shown in Figure 8, for various pressure conditions, the steam condensation heat transfer coefficient on the vertical wall decreases with the increase of the mass fraction of $\mathrm{N}_{2}$ / Ar. In Figure 8(a), when the pressure is $0.517 \mathrm{MPa}$ and the mass fraction of $\mathrm{N}_{2}$ is $9.03 \%$, the condensation heat transfer coefficient is $1.393 \mathrm{~kW} /\left(\mathrm{m}^{2} \cdot \mathrm{K}\right)$. And as the mass fraction of $\mathrm{N}_{2}$ increases to $75.76 \%$, the condensation heat transfer coefficient is reduced to $0.165 \mathrm{~kW} /\left(\mathrm{m}^{2} \cdot \mathrm{K}\right)$. For the other pressure conditions, the condensation heat transfer

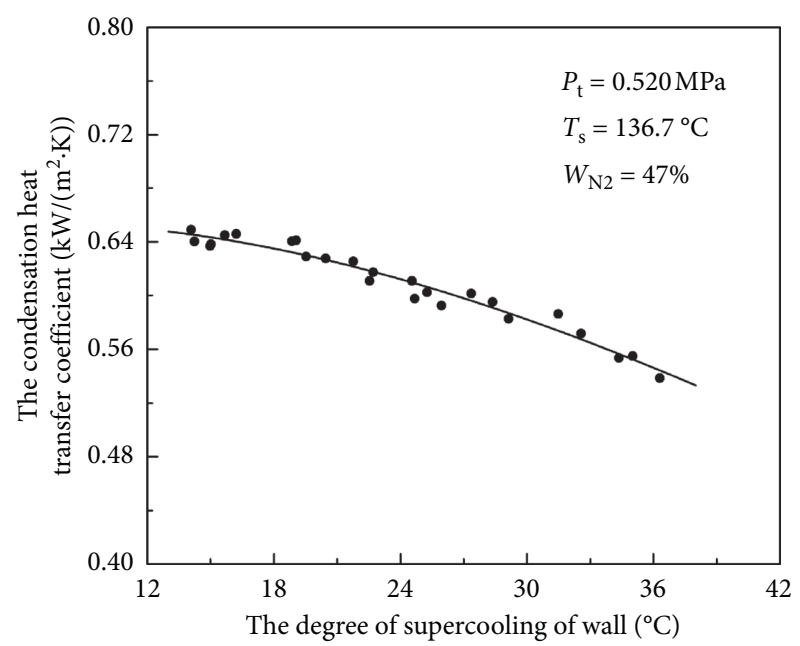

FIgURE 7: The effect of degree of supercooling of the wall on steam condensation.

coefficients show the same law of change. In Figure 8(b), the condensation heat transfer coefficients under different pressure in the presence of Ar are given and have a similar feature with those in the presence of $\mathrm{N}_{2}$.

\subsubsection{Effect of the Molar Fraction of Noncondensable Gas.} As shown in Figure 9, the steam condensation heat transfer coefficient on the vertical wall also decreases as the molar fraction of $\mathrm{N}_{2} / \mathrm{Ar}$ increases for various pressure. For example, it is indicated that the steam condensation heat transfer coefficient is $4.51 \mathrm{~kW} /\left(\mathrm{m}^{2} \cdot \mathrm{K}\right)$ for the pressure of $2.13 \mathrm{MPa}$ and the $\mathrm{N}_{2}$ molar fraction of $3.83 \%$ in Figure 9(a). However, when the molar fraction of $\mathrm{N}_{2}$ increases to $81.2 \%$, the associated steam condensation heat transfer coefficient decreases to $0.187 \mathrm{~kW} /\left(\mathrm{m}^{2} \cdot \mathrm{K}\right)$. And in the cases of other pressure or the noncondensable gas being Ar, the steam condensation heat transfer has the same law of change. It is obvious that the effects of the molar fraction of the noncondensable gas are consistent with the effects of the mass fraction of the noncondensable gas on the steam condensation heat transfer coefficient on the vertical wall.

\subsection{Effect of the Pressure on Steam Condensation Heat} Transfer. The effect of pressure on the heat transfer of steam condensation with nitrogen is shown in Figure 10. It is indicated that the heat transfer coefficients of steam condensation increase with the increase of pressure; namely, the pressure can enhance the heat transfer of steam condensation. For instance, when the mass fraction of nitrogen is $20 \%$, the heat transfer coefficient is $0.757 \mathrm{~kW} /\left(\mathrm{m}^{2} \cdot \mathrm{K}\right)$ for pressure $0.214 \mathrm{MPa}$ and $4.26 \mathrm{~kW} /\left(\mathrm{m}^{2} \cdot \mathrm{K}\right)$ for pressure $5.12 \mathrm{MPa}$. What is more, the curves of heat transfer coefficient with pressure have a larger slope in the low-pressure region, and the slope decreases with the increase of pressure. 


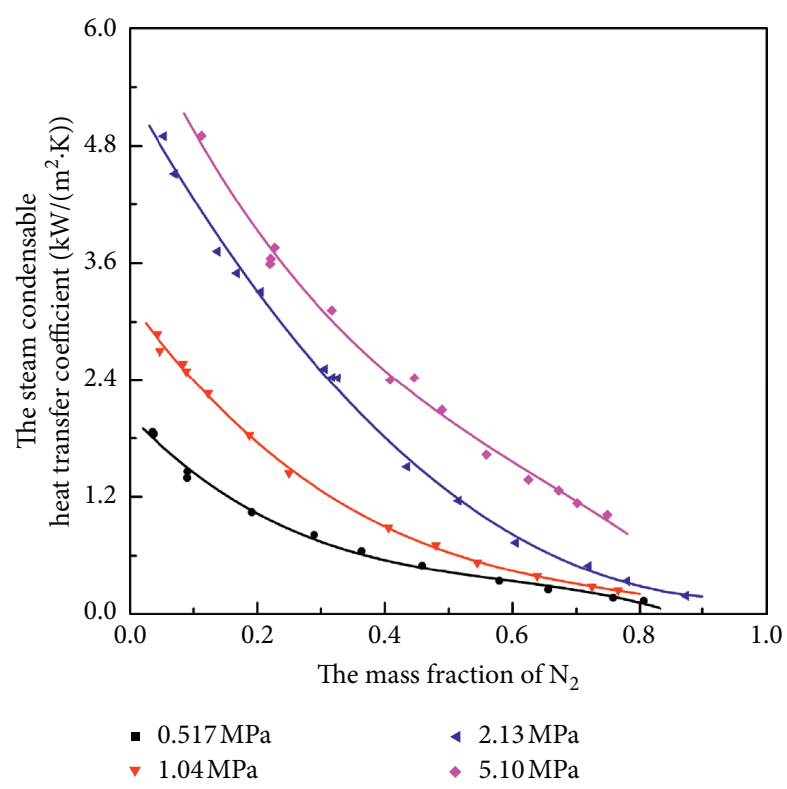

(a)

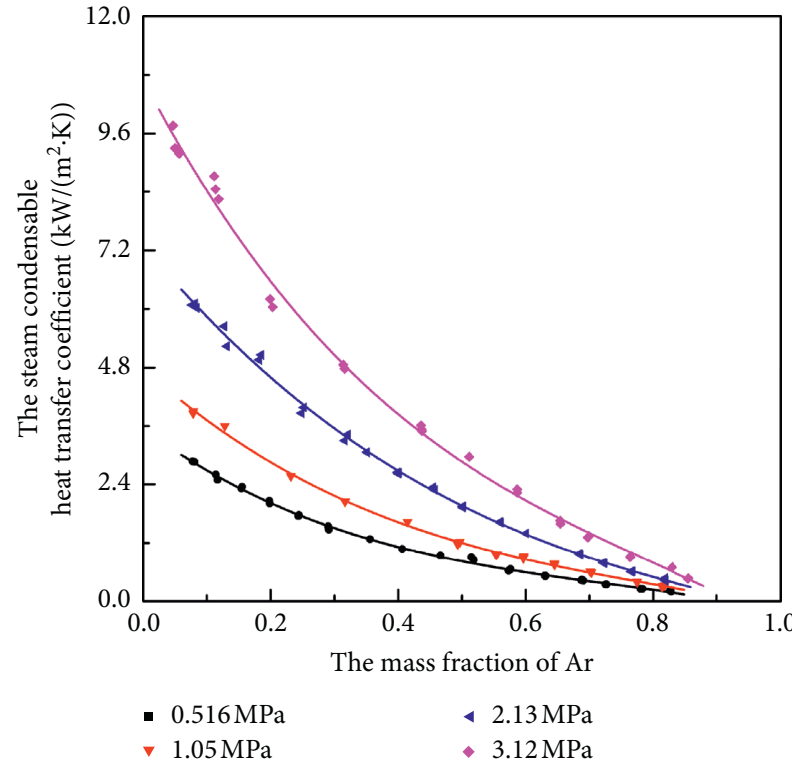

(b)

Figure 8: Effects of the mass fraction of noncondensable gas. (a) $\mathrm{N}_{2}$. (b) Ar.

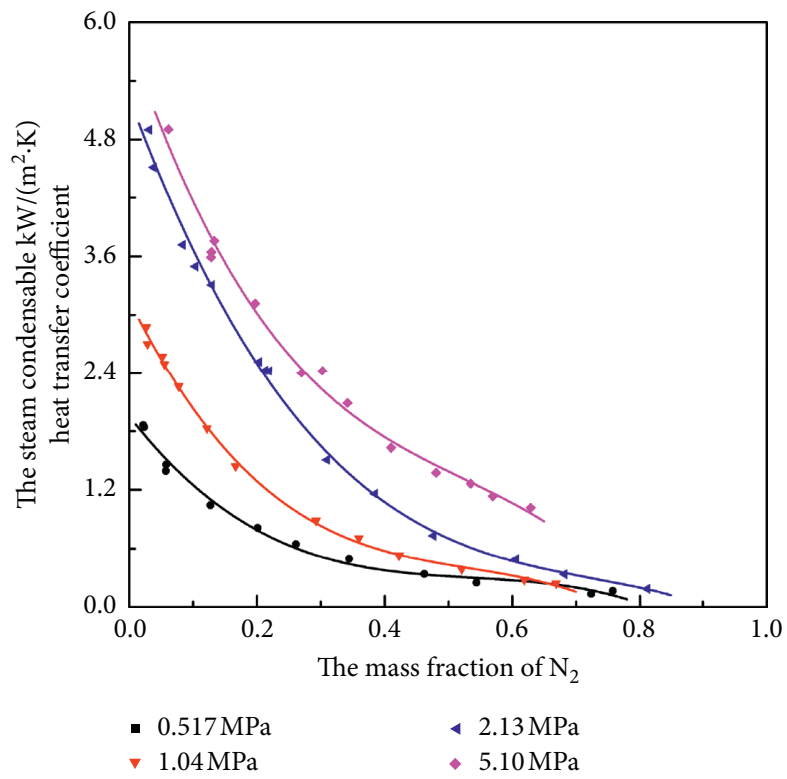

(a)

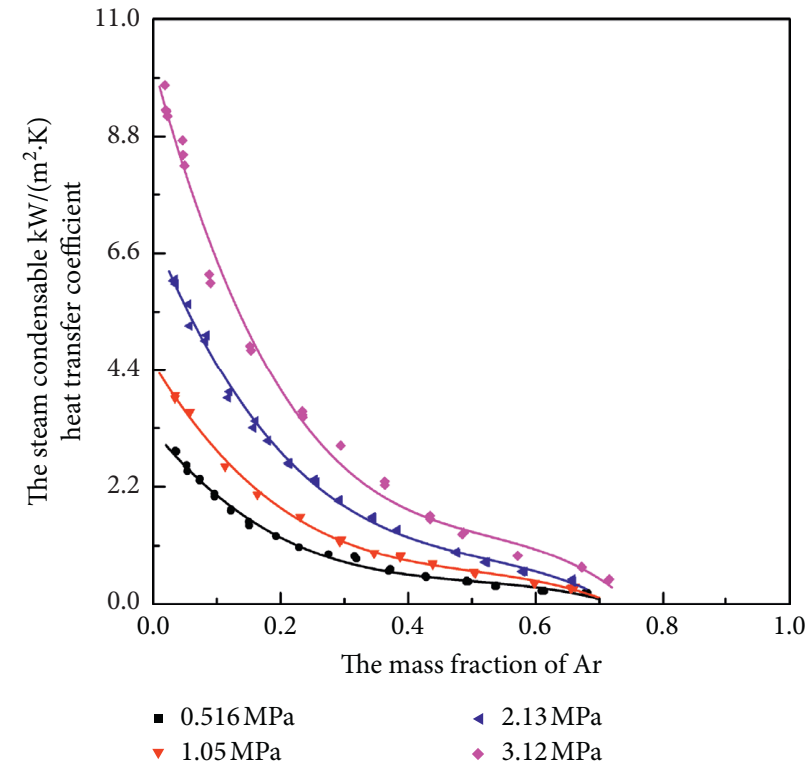

(b)

FIgURE 9: Effects of the molar fraction of noncondensable gas. (a) $\mathrm{N}_{2}$. (b) Ar.

That is, the enhancement of pressure on steam condensation heat transfer is obvious in the low-pressure region, and its enhancement weakens gradually with the increase of pressure. It is also obtained that the curves of steam condensation heat transfer coefficient with pressure are very close to the logarithmic function curves when the mass fraction of nitrogen is less than $50 \%$. However, the curves begin to be irregular when the mass fraction of nitrogen is from $50 \%$ to $80 \%$.

Figure 11 shows the effect of pressure on the heat transfer of steam condensation with argon. The pressure has a similar enhancement on steam condensation for argon with that for nitrogen. It is also found that the curves of steam 


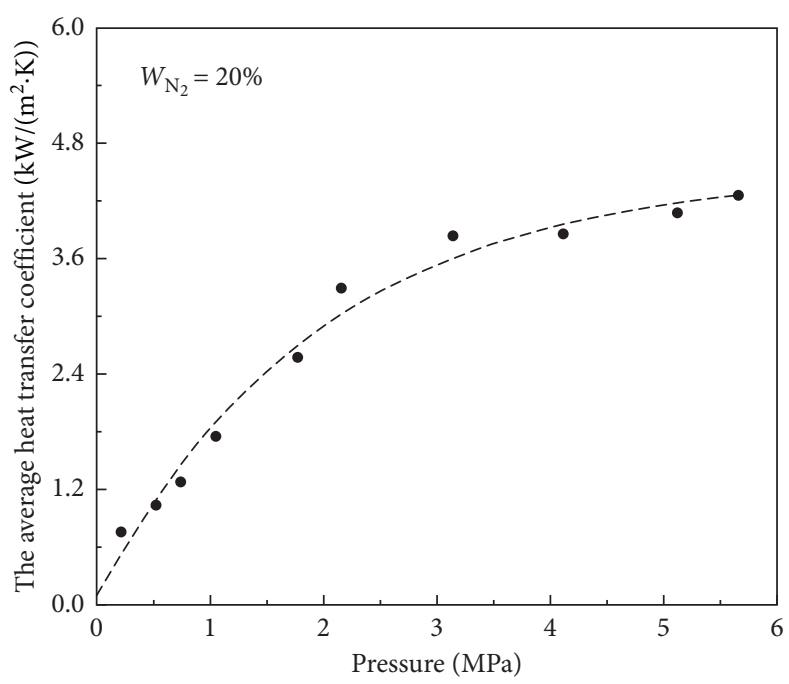

(a)

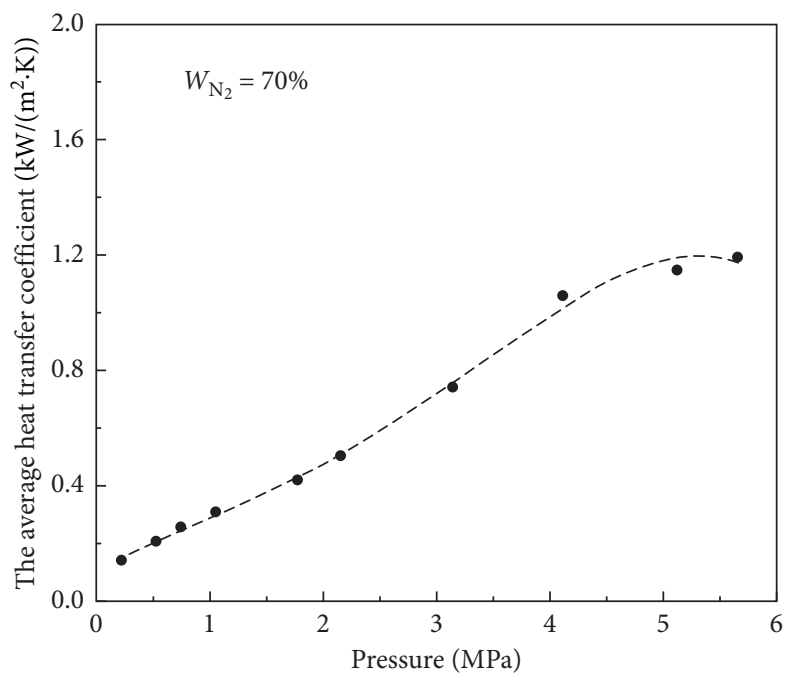

(c)

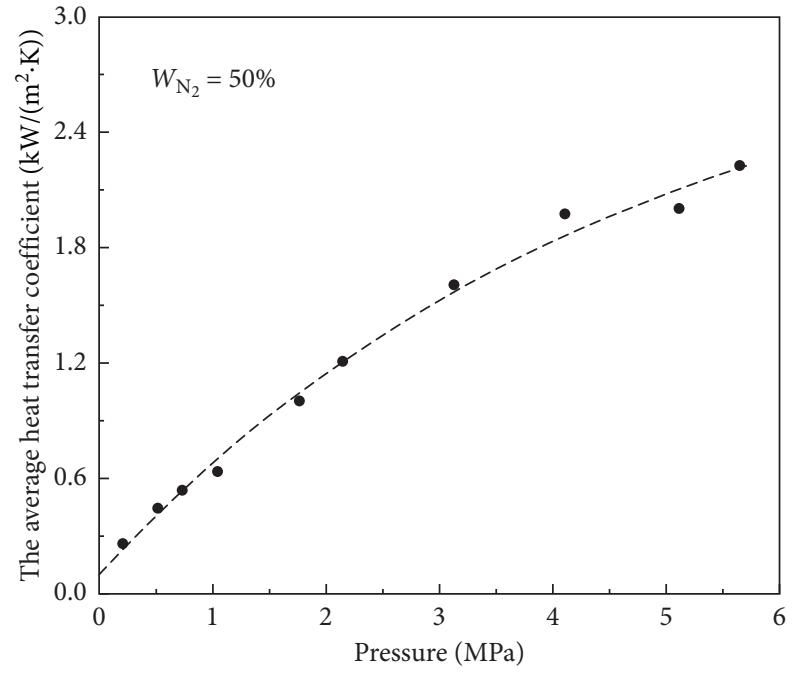

(b)

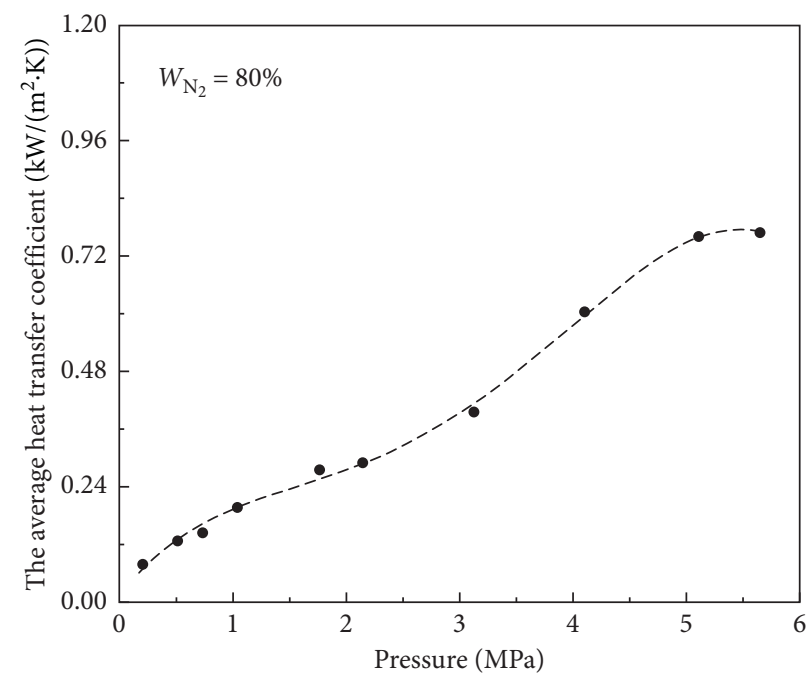

(d)

FIGURE 10: Effect of pressure on the steam condensation with $\mathrm{N}_{2}$. (a) $W_{\mathrm{N} 2}=20 \%$. (b) $W_{\mathrm{N} 2}=50 \%$. (c) $W_{\mathrm{N} 2}=70 \%$. (d) $W_{\mathrm{N} 2}=80 \%$.

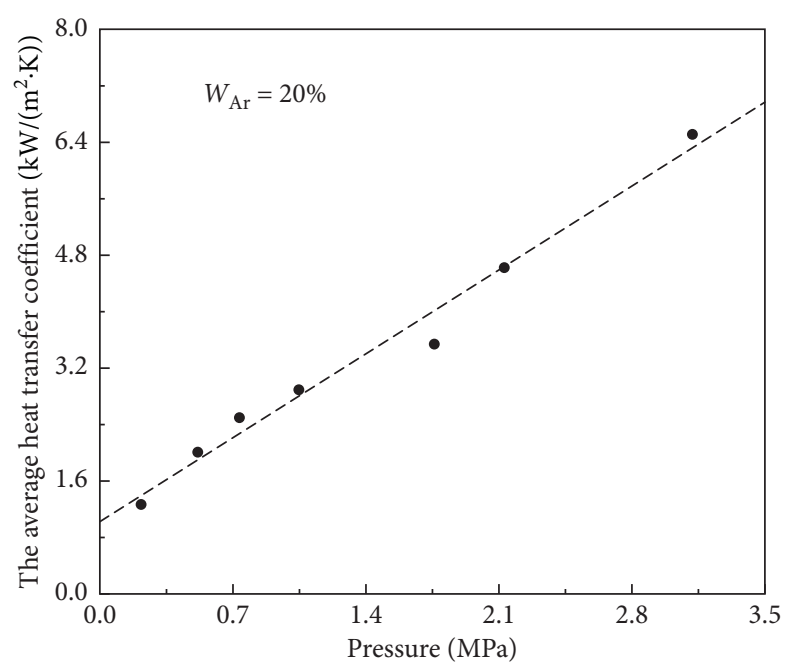

(a)

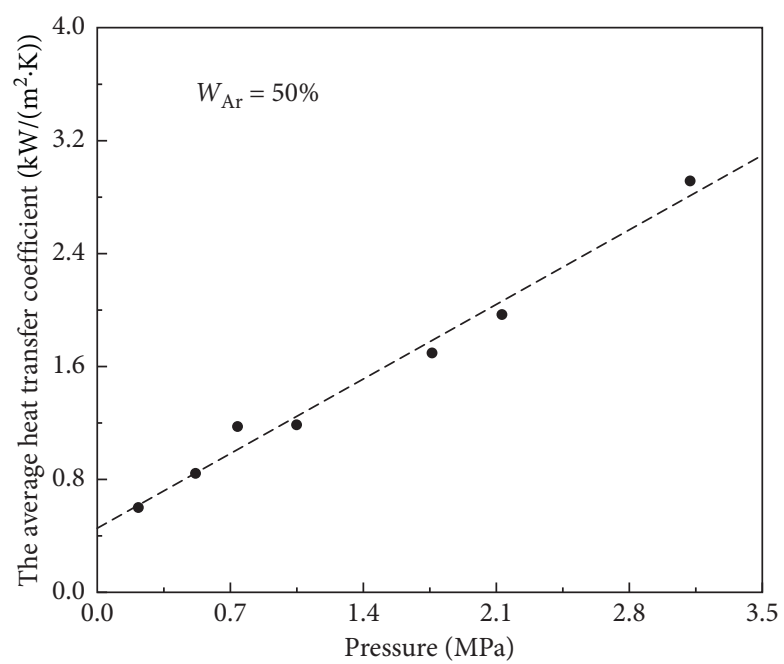

(b)

FIgURE 11: Continued. 


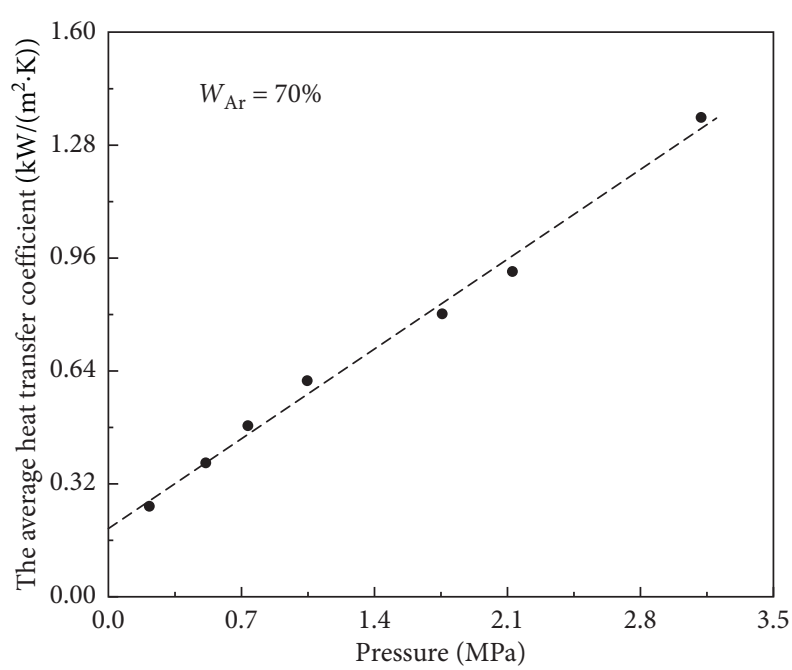

(c)

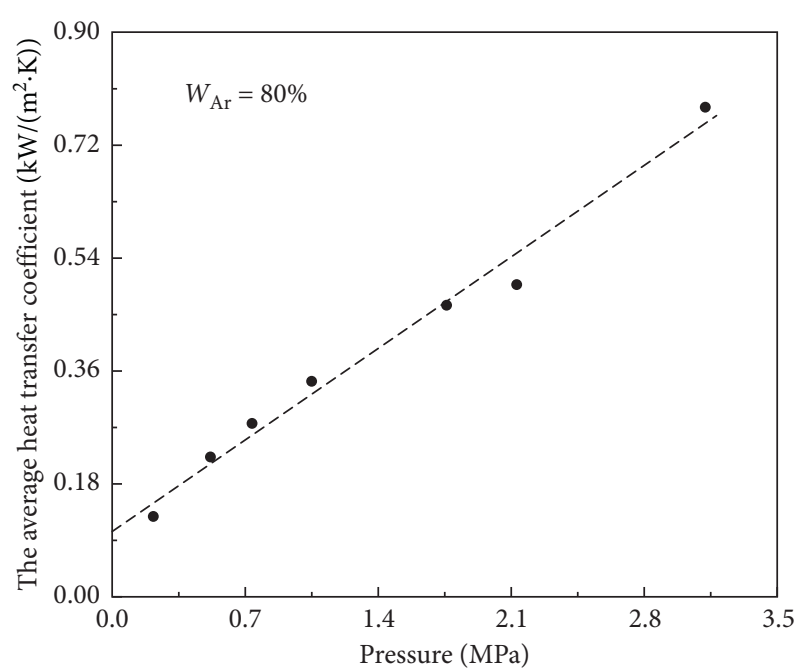

(d)

Figure 11: Effect of pressure on the steam condensation with Ar.

(a) $W_{\mathrm{Ar}}=20 \%$. (b) $W_{\mathrm{Ar}}=50 \%$. (c) $W_{\mathrm{Ar}}=70 \%$. (d) $W_{\mathrm{Ar}}=80 \%$.

condensation heat transfer coefficient with pressure are very close to the linear function curves with the pressure from 0.2 to $3.1 \mathrm{MPa}$. And, the curves are very close to the linear function curves when the mass fraction of argon is from $20 \%$ to $80 \%$, which is different from those with nitrogen.

\section{Conclusions}

An experimental system had been established to investigate the heat transfer characteristics of steam condensation in presence of noncondensable gas under natural convection. The effects of $\mathrm{N}_{2}$ and Ar on the steam condensation were investigated, the pressure ranged from 0.516 to $5.10 \mathrm{MPa}$, and the mass fraction of nitrogen/argon varied from $5 \%$ to $85 \%$. According to the experimental results, some conclusions were obtained as follows:

(1) The spatial distributions of $\mathrm{N}_{2}$ and $\mathrm{Ar}$ in the steam/ gas mixture were relatively uniform and there was no obvious stratification phenomenon. When the primary pressure varied from 0.517 to $5.10 \mathrm{MPa}$ and the gas temperature varied from $110^{\circ} \mathrm{C}$ to $249^{\circ} \mathrm{C}$, the differences in the mass fraction of nitrogen/argon in the axial direction were less than $2.7 \%$ and had similar trends when the axial distance increased.

(2) When the pressure was $0.52 \mathrm{MPa}$ and the mass fraction of nitrogen was $47 \%$, the total heat transfer coefficient of steam condensing on the wall was $0.215 \mathrm{~kW} /\left(\mathrm{m}^{2} \cdot \mathrm{K}\right)$ and the heat transfer coefficient remained basically unchanged with the increase of the total heat transfer temperature difference. The heat transfer coefficient of steam condensation decreased with the increase of the degree of supercooling of the wall. The difference of steam condensation heat transfer coefficient was approximately $0.11 \mathrm{~kW} /$ $\left(\mathrm{m}^{2} \cdot \mathrm{K}\right)$ when the degree of supercooling increased from $14^{\circ} \mathrm{C}$ to $36^{\circ} \mathrm{C}$. Therefore, the influences of total heat transfer temperature difference on the steam condensation could be ignored, while the degree of supercooling of the wall should be controlled in a very small range as far as possible during the experiments.

(3) The concentration of noncondensable gas was a vital factor affecting the heat and mass transfer in steam condensation. When the pressure was $0.517 \mathrm{MPa}$ and the mass fraction of nitrogen varied from $9.03 \%$ to $75.76 \%$, the condensation heat transfer coefficient decreased from 1.393 to $0.165 \mathrm{~kW} /\left(\mathrm{m}^{2} \cdot \mathrm{K}\right)$. For the other pressure conditions and argon, the steam condensation heat transfer coefficients showed the same law of change. And it is obvious that the effects of the molar fraction of the noncondensable gas were consistent with the effects of the mass fraction of the noncondensable gas on the steam condensation heat transfer coefficient on the vertical wall.

(4) The pressure also played a key role in the heat transfer of steam condensation with noncondensable gas. The pressure was able to greatly enhance the steam condensation heat transfer; for example, the heat transfer coefficient with $\mathrm{N}_{2}$ varied from 0.757 to $4.26 \mathrm{~kW} /\left(\mathrm{m}^{2} \cdot \mathrm{K}\right)$ for the pressure from $0.214 \mathrm{MPa}$ to $5.12 \mathrm{MPa}$. However, the characteristics of enhancement of pressure on steam condensation heat transfer were a little different for $\mathrm{N}_{2}$ and $\mathrm{Ar}$.

\section{Data Availability}

The data are not available due to the trade secret. 


\section{Conflicts of Interest}

The authors declare that there are no conflicts of interest regarding the publication of this paper.

\section{Acknowledgments}

This work was supported by the Science and Technology Plan Project of Administration for Market Regulation of Henan Province (Grant no. 2020sj62) and the Basic Scientific Research Business Fee Supporting Project of Henan Province (Grant no. 2020ky32).

\section{References}

[1] Power Reactor Country Statistics: People's Republic of China [EB/OL]. [2017-02-12]. https://www.iaea.org/PRIS/ CountryStatistics/CountryDetails.aspx?current=CN.

[2] International Atomic Energy Agency, Advances in Small Modular Reactor Technology Developments, International Atomic Energy Agency, Vienna, Austria, 2014.

[3] D. Wang, D. Dong, W. Zheng et al., "The $200 \mathrm{MW}$ nuclear heating reactor and its possible application in seawater desalination," Desalination, vol. 99, no. 2-3, pp. 383-399, 1994.

[4] W. Zheng and D. Wang, "Design characteristics and safety concept of nuclear heating reactor in China," Nuclear Science and Engineering, vol. 15, no. 4, pp. 317-324, 1995.

[5] J.-W. Kim, Y.-G. Lee, H.-K. Ahn, and G.-C. Park, "Condensation heat transfer characteristic in the presence of noncondensable gas on natural convection at high pressure," Nuclear Engineering and Design, vol. 239, no. 4, pp. 688-698, 2009.

[6] D. F. Othmer, "The condensation of steam," Industrial \& Engineering Chemistry, vol. 21, no. 6, pp. 576-583, 1929.

[7] H. Uchida, A. Oyama, and Y. Togo, Evaluation of Post-Incident Cooling Systems of Light Water Power Reactors, p. 436, Tokyo University, Tokyo, Japan, 1964.

[8] T. Tagami, Interim Report on Safety Assessments and Facilities Establishment Project for June 1965, Japanese Atomic Energy Research Agency, Tokai, Japan, 1965.

[9] I. K. Huhtiniemi and M. L. Corradini, "Condensation in the presence of noncondensable gases," Nuclear Engineering and Design, vol. 141, no. 3, pp. 429-446, 1993.

[10] H. Anderson Mark, L. E. Herranz, and M. L. Corradini, "Experimental analysis of heat transfer within the AP600 containment under postulated accident conditions," Nuclear Engineering and Design, vol. 185, no. 2-3, pp. 153-172, 1998.

[11] S. V. Garimella and R. N. Christensen, "Transient condensation in the presence of noncondensables at a vertical wall," Nuclear Technology, vol. 89, no. 3, pp. 388-398, 1990.

[12] H. K. Al-Diwany and J. W. Rose, "Free convection film condensation of steam in the presence of non-condensing gases," International Journal of Heat and Mass Transfer, vol. 16, no. 7, pp. 1359-1369, 1973.

[13] H. Liu, N. E. Todreas, and M. J. Driscoll, “An experimental investigation of a passive cooling unit for nuclear plant containment," Nuclear Engineering and Design, vol. 199, no. 3, pp. $243-255,2000$.

[14] F. Votta Jr. and C. A. Walker, "Condensation of vapor in the presence of noncondensing gas," AICHE Journal, vol. 4, no. 4, pp. 413-417, 1958.

[15] S. Mansoor, M. W. Golay, and M. S. Kazimi, "Local heat transfer coefficients for forced-convection condensation of steam in a vertical tube in the presence of a noncondensable gas," Nuclear Technology, vol. 102, no. 3, pp. 386-402, 1993.

[16] G. Li, "Condensation heat transfer of steam in the presence of high content non-condensable gas outside of a horizontal three-dimensional finned tube," M.Sc. Thesis, Chongqing University, Chongqing, China, 2006.

[17] A. Chamkha, A. S. Dogonchi, and D. D. Ganji, "Magnetohydrodynamic nanofluid natural convection in a cavity under thermal radiation and shape factor of nanoparticles impacts: a numerical study using CVFEM," Applied Sciences, vol. 8, no. 12, p. 2396, 2018.

[18] M. N. Kumar, Studies on passive containment cooling system of Indian advanced heavy water reactor, Ph.D. Thesis, Tokyo Institute of Technology, Tokyo, Japan, 2006.

[19] H. W. Hu, G. H. Tang, and D. Niu, "Experimental investigation of convective condensation heat transfer on tube bundles with different surface wettability at large amount of noncondensable gas," Applied Thermal Engineering, vol. 100, pp. 699-707, 2016.

[20] A. A. Dehbi, The effects of noncondensable gases on steam condensation under turbulent natural convection conditions, Ph.D. Thesis, Massachusetts Institute of Technology, Cambridge, MA, USA, 1991.

[21] D. Zhang, "Investigation on condensation of steam in the presence of air outside a vertical smooth tube," M.Sc. Thesis, Harbin Engineering University, Harbin, China, 2013.

[22] H. D. B. Jenkins, "Ideal and real gases. Dalton's law of partial pressures," Chemical Thermodynamics at a Glance, John Wiley \& Sons, Hoboken, NJ, USA, 2008.

[23] Incropera, P. Frank, and D. P. De Witt, Fundamentals of Heat and Mass Transfer, Wiley, Hoboken, NJ, USA, 4th edition, 1996.

[24] M. M. Peiravi, "Numerical study of fins arrangement and nanofluids effects on three-dimensional natural convection in the cubical enclosure," Transport Phenomena in Nano and Micro Scales, vol. 7, no. 2, pp. 97-112, 2019.

[25] M. M. Peiravi, J. Alinejad, D. D. Ganji, and S. Maddah, “3D optimization of baffle arrangement in a multi-phase nanofluid natural convection based on numerical simulation," International Journal of Numerical Methods for Heat \& Fluid Flow, vol. 30, no. 5, pp. 2583-2605, 2019. 